\title{
Supplement
}

This is a supplement accompanying the paper:

Redressing the balance: quantifying net intercatchment groundwater flows in the Meuse basin

by Laurène Bouaziz, Albrecht Weerts, Jaap Schellekens, Eric Sprokkereef, Jasper Stam, Hubert Savenije and Markus Hrachowitz

The supplement provides details on the water balance equations, constitutive functions and the model parameters (including prior and posterior distributions). Additionally, the supplement contains an analysis of the inter-annual variability of net intercatchment groundwater flow processes.

1 Model equations

2 Prior and posterior parameter distributions

3 Inter-annual variability of net intercatchment groundwater flows 


\section{Model equations}

Symbols used to define the different fluxes and stores in the model schematizations (see Figure 4 of the paper) are detailed in Table 1 and Table 2, definitions of the symbols used for the parameters are provided in Section 2 of the Supplement. Water balance and constitutive equations of the zero, constant, preferential and overflow intercatchment groundwater flows models are provided in Table 3 and in Table 4.

Table 1: Definitions of the symbols used to denote the different fluxes in the models.

\begin{tabular}{ll}
\hline Fluxes $\left(\mathrm{mm} \mathrm{hr}^{-1}\right)$ & Definition \\
\hline$P$ & Precipitation \\
$E_{I}$ & Evaporation from interception \\
$E_{U}$ & Evaporation from the root zone storage \\
$R_{I U}$ & Effective precipitation \\
$R_{U S}$ & Recharge to the slow reservoir \\
$R_{U F}$ & Recharge to the fast reservoir \\
$R_{P}$ & Percolation \\
$Q_{F}$ & Fast runoff \\
$Q_{S}$ & Slow runoff \\
$Q_{R i v e r}$ & Discharge which ends up in the river \\
$Q_{I G F, \text { constant }}$ & Net constant intercatchment groundwater flows \\
$Q_{I G F, \text { pref. }}$ & Net preferential intercatchment groundwater flows \\
$Q_{I G F}$ & Net intercatchment groundwater flows from overflow model \\
\hline
\end{tabular}

Table 2: Definitions of the symbols used to denote the different stores in the models.

\begin{tabular}{ll}
\hline Stores $(\mathrm{mm})$ & Definition \\
\hline$S_{I}$ & Interception storage \\
$S_{U}$ & Root zone storage \\
$S_{F}$ & Fast reservoir store \\
$S_{S}$ & Slow reservoir store \\
\hline
\end{tabular}


Table 3: Water balance equations. The $\checkmark$ indicates for which model(s) the water balance equations apply.

\begin{tabular}{lcccc}
\hline Water balance equation & Zero & Constant & Preferential & Overflow \\
\hline$\frac{\mathrm{d} S_{I}}{\mathrm{~d} t}=P-E_{I}-R_{I U}$ & $\checkmark$ & $\checkmark$ & $\checkmark$ & $\checkmark$ \\
$\frac{\mathrm{d} S_{U}}{\mathrm{~d} t}=R_{I U}-E_{U}-R_{P}-R_{U S}-R_{U F}$ & $\checkmark$ & $\checkmark$ & $\checkmark$ & \\
$\frac{\mathrm{d} S_{U}}{\mathrm{~d} t}=R_{I U}-E_{U}-R_{U S}$ & & & & $\checkmark$ \\
$\frac{\mathrm{d} S_{F}}{\mathrm{~d} t}=R_{U F}-Q_{F}$ & $\checkmark$ & $\checkmark$ & $\checkmark$ & \\
$\frac{\mathrm{d} S_{F}}{\mathrm{~d} t}=R_{S F}-Q_{\text {River }}$ & $\checkmark$ & & & $\checkmark$ \\
$\frac{\mathrm{d} S_{S}}{\mathrm{~d} t}=R_{U S}+R_{P}-Q_{S}$ & & $\checkmark$ & $\checkmark$ & \\
$\frac{\mathrm{d} S_{S}}{\mathrm{~d} t}=R_{U S}+R_{P}-Q_{S}-Q_{I G F}$ & & & & $\checkmark$ \\
$\frac{\mathrm{d} S_{S}}{\mathrm{~d} t}=R_{U S}-R_{S F}-Q_{I G F}$ & $\checkmark$ & $\checkmark$ & $\checkmark$ & \\
$Q_{\text {River }}=Q_{S}+Q_{F}$ & $\checkmark$ & $\checkmark$ & $\checkmark$ & $\checkmark$ \\
$Q_{T \text { ot }}=Q_{\text {River }}+Q_{I G F}$ & & & \\
\hline
\end{tabular}

Table 4: Constitutive functions. The $\checkmark$ indicates for which model(s) the constitutive functions apply. The following values are fixed for the smoothing parameters $\mathrm{m}_{1}=\mathrm{m}_{2}=\mathrm{m}_{4}=0.005$ and $\mathrm{m}_{3}=0.05$ ( $\sigma$ value of the error function).

\begin{tabular}{|c|c|c|c|c|}
\hline Constitutive functions & Zero & Constant & Preferential & Overflow \\
\hline$\overline{S_{I}}=\frac{S_{I}}{I_{\max }}$ & $\checkmark$ & $\checkmark$ & $\checkmark$ & $\checkmark$ \\
\hline$\overline{S_{U}}=\frac{S_{U}}{S_{U, \max }}$ & $\checkmark$ & $\checkmark$ & $\checkmark$ & $\checkmark$ \\
\hline$\overline{S_{S}}=\frac{S_{S}}{S_{S, \max }}$ & & & & $\checkmark$ \\
\hline$E_{I}=E_{P} \cdot \frac{\overline{S_{I}} \cdot\left(1+m_{1}\right)}{\overline{S_{I}}+m_{1}}$ & $\checkmark$ & $\checkmark$ & $\checkmark$ & $\checkmark$ \\
\hline$R_{I U}=P \cdot\left(1-\frac{\left(1-S_{I}\right)\left(1+m_{2}\right)}{1-\overline{S_{I}}+m_{2}}\right)$ & $\checkmark$ & $\checkmark$ & $\checkmark$ & $\checkmark$ \\
\hline$E_{U}=\left(E_{P}-E_{I}\right) \cdot \frac{\overline{S_{U}}}{L_{p}}$ & $\checkmark$ & $\checkmark$ & $\checkmark$ & $\checkmark$ \\
\hline$R_{U}=R_{U S}+R_{U F}$ & $\checkmark$ & $\checkmark$ & $\checkmark$ & \\
\hline$R_{U}=P \cdot{\overline{S_{U}}}^{\beta}$ & $\checkmark$ & $\checkmark$ & $\checkmark$ & \\
\hline$R_{U S}=R_{U} \cdot d$ & $\checkmark$ & $\checkmark$ & $\checkmark$ & \\
\hline$R_{U F}=R_{U} \cdot(1-d)$ & $\checkmark$ & $\checkmark$ & $\checkmark$ & \\
\hline$R_{P}=P_{\max } \cdot \overline{S_{U}}$ & $\checkmark$ & $\checkmark$ & $\checkmark$ & \\
\hline$Q_{F}=K_{F}^{-1} \cdot S_{F}^{\alpha}$ & $\checkmark$ & $\checkmark$ & $\checkmark$ & \\
\hline$Q_{S}=K_{S}^{-1} \cdot S_{S}$ & $\checkmark$ & $\checkmark$ & $\checkmark$ & \\
\hline$Q_{I G F}=C_{I G F}$ & & $\checkmark$ & & \\
\hline$Q_{I G F}=\operatorname{erf}\left(R_{U S}, \mu, m_{3}\right) \cdot P_{e r c} \cdot R_{U S}$ & & & $\checkmark$ & \\
\hline$Q_{I G F}=K_{I G F}^{-1} \cdot S_{S}$ & & & & $\checkmark$ \\
\hline$R_{U S}=P \cdot{\overline{S_{U}}}^{\beta}$ & & & & $\checkmark$ \\
\hline$R_{S F}=R_{U S} \cdot \frac{\overline{S_{S}} \cdot\left(1+m_{4}\right)}{\overline{S_{S}}+m_{4}}$ & & & & $\checkmark$ \\
\hline$Q_{\text {River }}=K_{\text {River }}^{-1} \cdot S_{F}$ & & & & $\checkmark$ \\
\hline
\end{tabular}




\section{Prior and posterior parameter distributions}

A description of model parameters, units and prior range is provided in Table 5. Posterior parameter ranges for the zero, constant and preferential models are given in Table 6. For the Aroffe catchment, the posterior parameter distributions of the overflow model are shown in Table 7.

Table 5: Model parameters, units and prior range $\left({ }^{*} \mathrm{MRC}\right.$ denotes the value determined with a master recession curve \pm 10 days). The $\checkmark$ indicates for which model(s) the parameters apply.

\begin{tabular}{|c|c|c|c|c|c|c|c|}
\hline Parameter & unit & Definition & Range & Zero & Constant & Preferential & Overflow \\
\hline$I_{\max }$ & $\mathrm{mm}$ & Maximum interception capacity & $1-3$ & $\checkmark$ & $\checkmark$ & $\checkmark$ & $\checkmark$ \\
\hline$S_{U, \max }$ & $\mathrm{mm}$ & Root zone storage capacity & $50-350$ & $\checkmark$ & $\checkmark$ & $\checkmark$ & $\checkmark$ \\
\hline$\beta$ & - & Shape parameter of storage capacity distribution & $1-5$ & $\checkmark$ & $\checkmark$ & $\checkmark$ & $\checkmark$ \\
\hline$L_{p}$ & - & Reduction parameter for potential evaporation & $0-1$ & $\checkmark$ & $\checkmark$ & $\checkmark$ & $\checkmark$ \\
\hline$K_{F}$ & $\mathrm{~h}$ & Characteristic time scale of the fast recession & $2-960$ & $\checkmark$ & $\checkmark$ & $\checkmark$ & \\
\hline$K_{S}$ & $\mathrm{~h}$ & Characteristic time scale of the slow recession & $\mathrm{MRC}^{*}$ & $\checkmark$ & $\checkmark$ & $\checkmark$ & \\
\hline$T_{F}$ & $\mathrm{~h}$ & Time lag & $1-20$ & $\checkmark$ & $\checkmark$ & $\checkmark$ & \\
\hline$d$ & - & Fraction to slow reservoir & $0-1$ & $\checkmark$ & $\checkmark$ & $\checkmark$ & \\
\hline$P_{\max }$ & $\mathrm{mm} \mathrm{h}^{-1}$ & Maximum percolation rate & $0-0.05$ & $\checkmark$ & $\checkmark$ & $\checkmark$ & \\
\hline$\alpha$ & - & Non linear coefficient of the fast reservoir & $1-2$ & $\checkmark$ & $\checkmark$ & $\checkmark$ & \\
\hline$C_{I G F}$ & $\mathrm{~mm} \mathrm{~h}^{-1}$ & Constant net intercatchment groundwater flow $\left(\mathrm{IGF}_{n e t}\right)$ & $-0.01-0.02$ & & $\checkmark$ & & \\
\hline$\mu$ & $\mathrm{mm} \mathrm{h}^{-1}$ & Threshold of the recharge above which IGF $_{n e t}$ occurs & $0.005-0.9$ & & & $\checkmark$ & \\
\hline$P_{\text {erc }}$ & - & Fraction of the recharge to $\mathrm{IGF}_{\text {net }}$ & $-0.5-1$ & & & $\checkmark$ & \\
\hline$K_{I G F}$ & $\mathrm{~h}$ & Characteristic time scale of the IGF $_{\text {net }}$ & $5-600$ & & & & $\checkmark$ \\
\hline$K_{\text {River }}$ & $\mathrm{h}$ & Characteristic time scale of the river flow & $5-600$ & & & & $\checkmark$ \\
\hline$S_{S, \max }$ & $\mathrm{mm}$ & Maximum capacity of underground stores & $1-60$ & & & & $\checkmark$ \\
\hline$d_{I G F}$ & - & Fraction to IGF $_{\text {net }}$ reservoir & $0.5-1$ & & & & $\checkmark$ \\
\hline
\end{tabular}


Table 6: Posterior parameter range (5-95 percentiles) for the zero, constant and preferential models for a selection of parameters

\begin{tabular}{|c|c|c|c|c|c|c|c|c|}
\hline $\begin{array}{l}\text { Parameter } \\
\text { Unit } \\
\text { Prior }\end{array}$ & $\begin{array}{c}S_{u, \max } \\
\mathrm{mm}\end{array}$ & $\begin{array}{c}L_{p} \\
-\end{array}$ & $\begin{array}{c}K_{F} \\
\mathrm{~h}\end{array}$ & $\begin{array}{l}d \\
-\end{array}$ & $\begin{array}{c}P_{\max } \\
\mathrm{mm} \mathrm{h}^{-1}\end{array}$ & $\alpha$ & $\begin{array}{c}C_{I G F} \\
\mathrm{~mm} \mathrm{~h}^{-1}\end{array}$ & $\begin{array}{l}P_{e r c} \\
-\end{array}$ \\
\hline Prior & $50-350$ & $0-1$ & $2-960$ & $0-1$ & $0-0.05$ & $1-2$ & $-0.01-0.02$ & $5-1$ \\
\hline Sainte-Marie - Zero & $224-324$ & $0.1-0.5$ & $108-908$ & $0.02-0.16$ & $0.007-0.020$ & $1.5-2.0$ & & \\
\hline Sainte-Marie - Constant & $220-309$ & $0.5-0.9$ & $83-747$ & $0.00-0.15$ & $0.016-0.038$ & $1.3-2.0$ & $0.004-0.016$ & \\
\hline Sainte-Marie - Pref. & $64-273$ & $0.0-0.8$ & $68-542$ & $0.17-0.42$ & $0.003-0.020$ & $1.1-1.9$ & & $0.7-1.0$ \\
\hline Straimont - Zero & $162-226$ & $0.1-0.5$ & $316-904$ & $0.07-0.18$ & $0.001-0.013$ & $1.2-1.6$ & & \\
\hline - Constant & $102-292$ & $0.0-0.9$ & $234-934$ & $0.06-0.20$ & $0.001-0.020$ & $1.1-1.5$ & $-0.003-0.006$ & \\
\hline Straimont - Pref. & $152-291$ & $0.1-0.7$ & $258-886$ & $0.03-0.16$ & $0.001-0.010$ & $1.1-1.5$ & & $-0.3-0.6$ \\
\hline Tintigny - Zero & $144-318$ & $0.3-0.8$ & $177-931$ & $0.02-0.12$ & $0.002-0.012$ & $1.2-1.6$ & & \\
\hline Tintigny - Constant & $125-248$ & $0.3-0.8$ & $151-896$ & $0.02-0.13$ & $0.002-0.028$ & $1.2-1.7$ & $-0.004-0.008$ & \\
\hline Tintigny - Pref. & $152-303$ & $0.4-0.8$ & $108-876$ & $0.03-0.20$ & $0.001-0.011$ & $1.1-1.6$ & & $-0.4-0.9$ \\
\hline Chiny - Zero & $166-283$ & $0.2-0.8$ & $203-948$ & $0.01-0.14$ & $0.003-0.016$ & $1.2-1.6$ & & \\
\hline Chiny - Constant & $140-314$ & $0.0-0.8$ & $182-901$ & $0.01-0.13$ & $0.003-0.025$ & $1.1-1.6$ & $-0.002-0.008$ & \\
\hline Chiny - Pref. & $111-268$ & $0.2-0.7$ & $122-865$ & $0.03-0.18$ & $0.004-0.016$ & $1.1-1.6$ & & $-0.4-0.9$ \\
\hline Membre-Pont - Zero & $114-232$ & $0.1-0.6$ & $307-884$ & $0.01-0.16$ & $0.004-0.022$ & $1.2-1.5$ & & \\
\hline Membre-Pont - Constant & $107-237$ & $0.0-0.7$ & $258-922$ & $0.01-0.14$ & $0.002-0.031$ & $1.2-1.5$ & $-0.005-0.003$ & \\
\hline Membre-Pont - Pref. & $129-260$ & $0.1-0.7$ & $195-919$ & $0.02-0.15$ & $0.004-0.020$ & $1.1-1.5$ & & $-0.4-0.9$ \\
\hline Huccorgne Pref. & $146-316$ & $0.3-0.8$ & $86-837$ & $0.07-0.52$ & $0.006-0.015$ & $1.3-1.8$ & & $-0.5-1.0$ \\
\hline Yvoir Pref. & $110-250$ & $0.4-0.9$ & $179-908$ & $0.39-0.65$ & $0.009-0.024$ & $1.4-1.9$ & & $0.7-0.9$ \\
\hline Sormonne Pref. & $119-299$ & $0.0-0.8$ & $70-818$ & $0.41-0.58$ & $0.000-0.017$ & $1.3-2.0$ & & $0.6-1.0$ \\
\hline Crusnes Pref. & $112-295$ & $0.2-0.7$ & $271-782$ & $0.36-0.58$ & $0.001-0.017$ & $1.0-1.4$ & & $0.4-0.9$ \\
\hline
\end{tabular}

Table 7: Posterior parameter range (5-95 percentiles) for overflow model used in the Aroffe catchment at Vannes-leChâtel

\begin{tabular}{lcccccccc}
\hline Parameter & $I_{\max }$ & $S_{u, \max }$ & $\beta$ & $L_{p}$ & $K_{\text {River }}$ & $K_{I G F}$ & $S_{S, \max }$ & $d_{I G F}$ \\
Unit & $\mathrm{mm}$ & $\mathrm{mm}$ & - & - & $\mathrm{h}$ & $\mathrm{h}$ & $\mathrm{mm}$ & - \\
Prior & $1-3$ & $50-350$ & $1-5$ & $0-1$ & $5-600$ & $5-600$ & $1-60$ & $0.5-1$ \\
\hline Aroffe - Overflow & $1.0-2.9$ & $88-210$ & $2.0-4.9$ & $0.2-0.8$ & $87-226$ & $212.7-594.1$ & $30.9-52.0$ & $0.75-0.83$ \\
\hline
\end{tabular}




\section{Inter-annual variability of net intercatchment groundwater flows}

The constant net intercatchment groundwater flow $\left(\mathrm{IGF}_{n e t}\right)$ model implies the same magnitude of IGF ${ }_{\text {net }}$ each year, while in the preferential model, $I_{\text {GF }}$ may vary inter-annually depending on meteorological conditions. Although meant for long term averages, the Budyko framework is shown for hydrological years in the Semois catchment at Sainte-Marie in Figure 1. Years with the highest precipitation amounts (2007 and 2012) plot beyond the energy limit, perhaps an indication that certain thresholds are exceeded and that more underground losses towards neighboring catchments occur in these years. Although the observed yearly variability may also be caused by changes in storage in the catchment, we consider that there may be years with more IGF $_{\text {net }}$ and

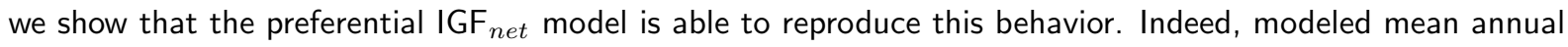
net losses using the preferential model increase as the distance to the energy limit of each hydrological year decreases, as shown in Figure 1.
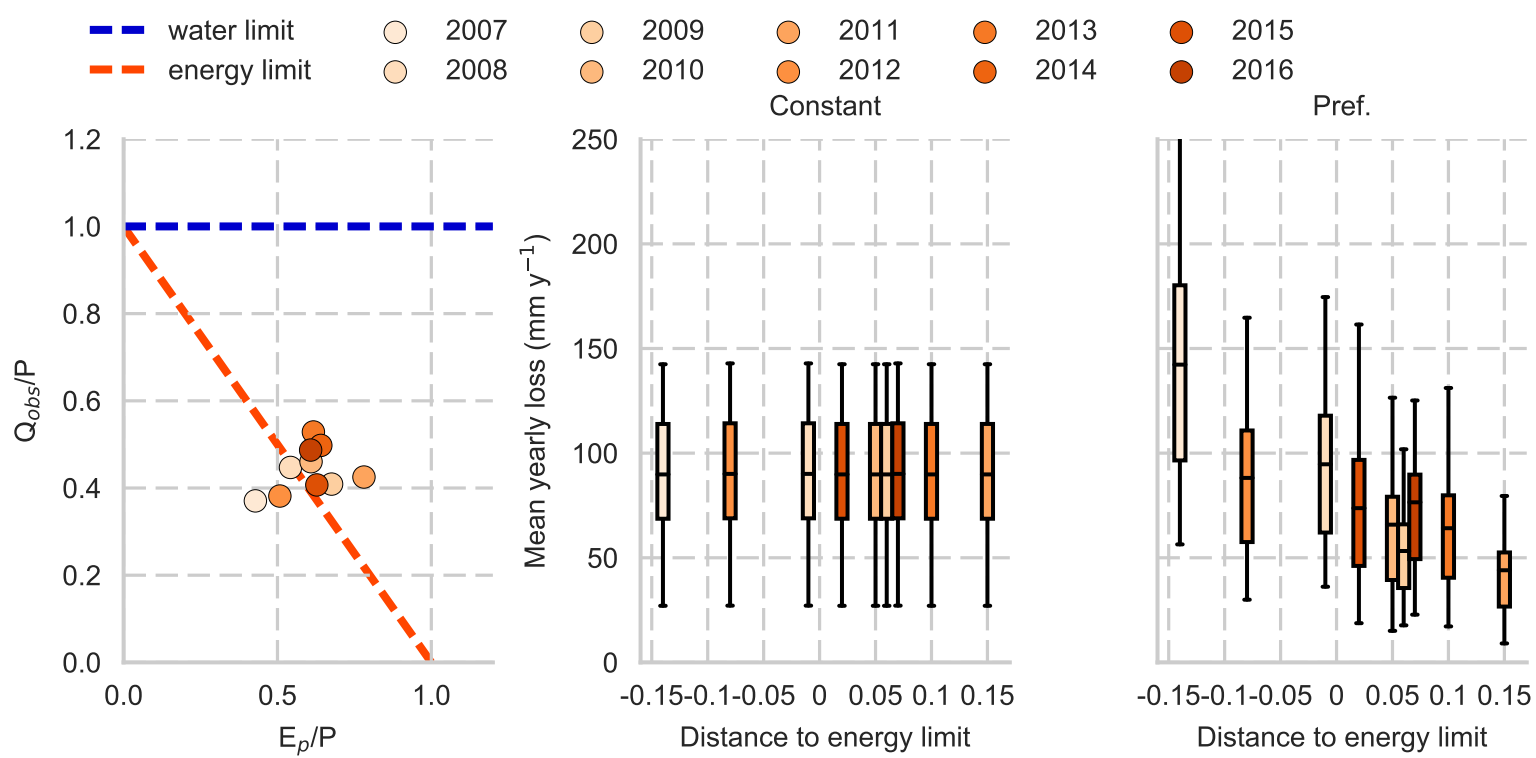

Figure 1: Left: dimensionless representation of the runoff coefficient $(Q o b s / P)$ as a function of the dryness index $\left(E_{p} / P\right)$, referred to as the Budyko framework, for hydrological years in the Semois catchment at Sainte-Marie. The blue line shows the water limit and the red line is the energy limit. Middle: mean yearly modeled net loss using the feasible realizations of the constant model as a function of the distance of each year to the energy line. Right: mean yearly modeled net loss using the feasible realizations of the preferential model as a function of the distance of each year to the energy line. The relation between the magnitude of the net loss and the distance to the energy line for each hydrological year shows that the preferential model is able to reproduce the observed inter-annual variability of the water balance by generating higher losses in years that plot beyond or close to the energy limit. 